Description, digitisation and metadata applied for post-mortem photographs in New Zealand Heritage Institutions

\title{
Lucy Gable
}

\begin{abstract}
Submitted to the School of Information Management, Victoria University of Wellington in partial fulfilment of the requirements for the degree of Master of Information Studies
\end{abstract}


Description, digitisation and metadata applied for post-mortem photographs in New Zealand Heritage Institutions. 


\section{Table of Contents}

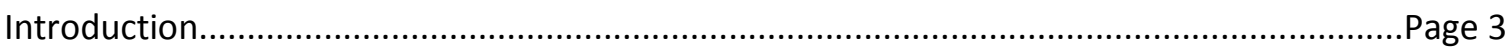

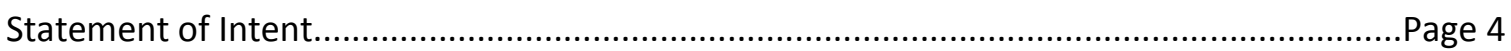

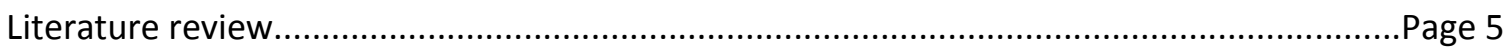

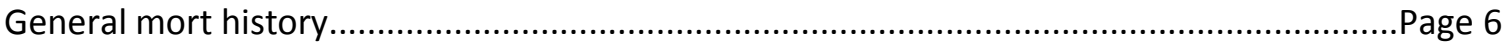

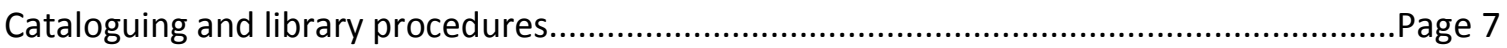

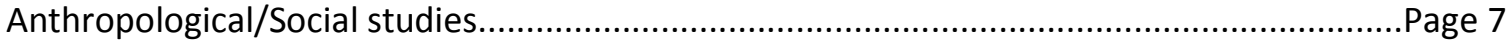

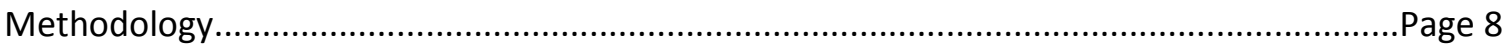

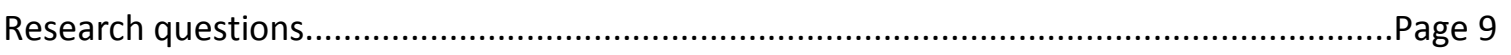

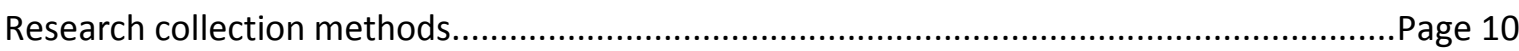

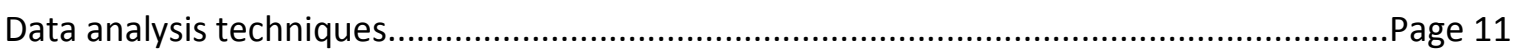

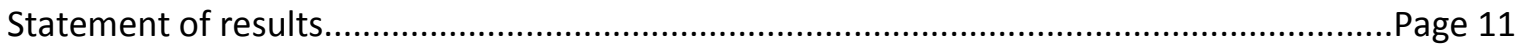

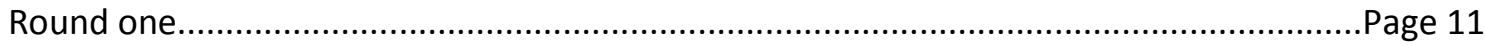

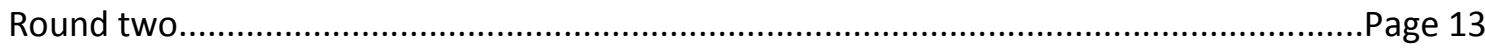

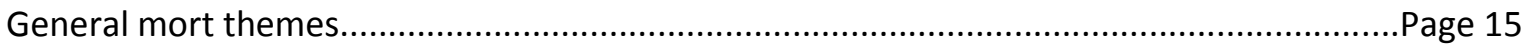

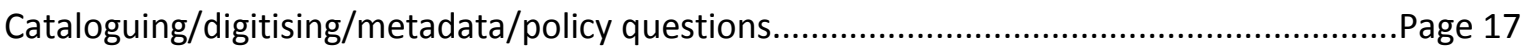

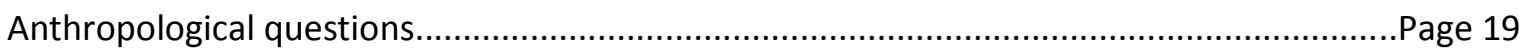

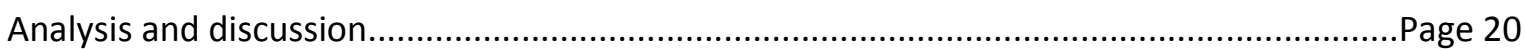

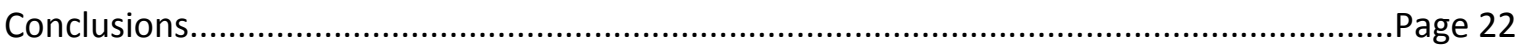

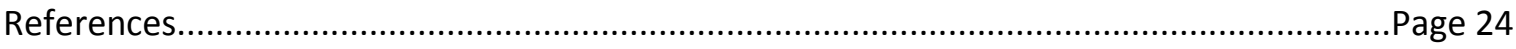

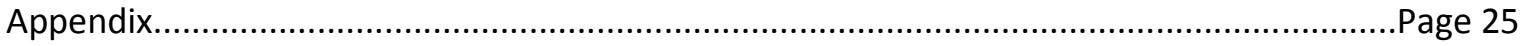




\section{Introduction}

Many impressions come to mind when beginning a study into the traditions popular during the late $19^{\text {th }}$ century; restriction, corsets, hard physical labour, over patterned wallpaper, top hats and black mourning clothes. Due to the high mortality rate during the late Victorian period a prolific number of traditions arose surrounding the way societies mourned, grieved and celebrated the people they loved when they passed away. Research into the unique blend of cultures which came together to establish modern New Zealand society offers many insights into a colonial country building its own identity, the traditions which remained and the ones which were discarded. The following piece of research will look at one such tradition, that of post-mortem photography. It took hold in the United States after being imported from Europe in the years following the invention of photography, around 1850. It was a tradition born out of soaring mortality rates, particularly of babies and young children and a need to "silence the unutterable grief, images recalled the physical presence of a dead child and taught mourning parents to feel some consolation for their loss." (Bown 2009)

In its early years photography was expensive, and the technology cumbersome. For many people a photographic portrait could only be afforded once or twice in a life time. It was common for children to die before there was an opportunity to have a portrait taken. Out of a need to retain an image of a departed loved one that postmortem photography was born. Over the years the style changed to represent the conventions of society and improvements in the business of death. Changes such as the eternal sleep pose giving way to photographs taken with the person laid out in their coffin surrounded by a sea of floral bouquets. After the Civil War, the popularity of embalming began a trend for large expensive funerals, an illustration of the love a family felt for the deceased. Coffins gave way to caskets and the humble posy was passed up for professional bouquets in a variety of shapes and designs, often depicting details of the deceased person's life - anchors, harps and wreaths were all popular with the Victorian public. Along with all the pomp and ceremony came the photographers, offering to retain the image of your loved one for the rest of your life. A person can see in such hard times how a photograph could mean so much and represent what was lost.

In keeping with such an exhibition of love and respect, institutions are required to educate their staff about the how and the why of mourning traditions so we may best do justice to them in our collections. 


\section{Statement of intent}

The intention of this study is to identify what criteria Photographic Curators/Pictorial Librarians in New Zealand Heritage Institutions use when cataloguing post-mortem photographs (mort photographs). In addition to the main intent, this study will endeavour to proffer theories about the popularity or lack of popularity of post-mortem photography in New Zealand during the years spanning 1870-1940. This time period, the late Victorian and Edwardian eras, heralded many cultural changes and saw post-mortem photography become a major part of mourning tradition in countries such as England, America and parts of Europe. Data will be gathered from the photographic cataloguing field on topics such as; the number of post-mortem photographs held in New Zealand collections; policies surrounding the collection and display of images of deceased people/animals (often under the policy umbrella of human remains, war and sensitive cultural topics) digitisation of these photographs and the style and processing of images available in New Zealand. By researching the institutional, historical and anthropological handling of mort photographs, the data will form theories as to how the tradition of mort photography was viewed in a New Zealand social context.

The value in this study will be two fold. Looking at the decisions cataloguers make when working with sensitive topics will initiate a discussion on policy surrounding the most sensitive areas of our photographic collections. By using post-mortem photographs as an example, the researcher will hypothesis theories as to how difficult subjects may be researched and approached for discussion in the institution and with the general public by using educating them and dispelling a long held taboo. The second point of value will be enhancing the understanding of aspects of early New Zealand society and how our distinctive cultural backgrounds has have moulded our present day traditions, beliefs and national identity.

The beneficial outcomes of this study are multi-faceted. In addition to the sociological insights, the researcher will endeavour to propose how an institution, such as the Auckland War Memorial Museum, can best catalogue, digitise and display items such as morts. The primary benefactor will be the Library at the Auckland War Memorial Museum as a case study based on this research will offer a series of guidelines on which a collections policy could be built for the acquisition, description and digitisation of a collection of post-mortem photographs. Another benefit of this study will be from undertaking research into the social history of New Zealand during its formative years. The topic of death and mourning in early New Zealand history has very little research at this point. Understanding death and how we have traditionally processed our grief will pose questions for further anthropological research such as traditions surrounding death and mourning, sociological studies into grief \& loss, visual ethnological studies into the inclusion of photographs as extant documents in historical research and information studies into the cataloguing and digitising of sensitive items. 


\section{Literature review}

There is not a wealth of critically sited research available on the topic of post-mortem photography. A number of small pieces of research have been done on the history of the topic, in addition to research on the visual anthropology of death and mourning such as Secure in the Shadow: Death and Photography in America by Jay Ruby (1995). I have been unable to find any case studies about the acquisition or cataloguing of post mortem photographs in a library, museum or archive collection. I have also been unable to find any research into post-mortem photography in a New Zealand context. There appears to be a gap in the research around the cataloguing of restricted or sensitive items. Research such as; the decisions an institution is required to make around the display and availability of sensitive photographs and any permissions required from relatives or Iwi (if the person has been identified). Within a New Zealand context I was unable to find any citable information around the tapu or spiritual restrictions around the photography of dead people.

It is due to the limited amount of specific research that I have chosen to open my review and look around the main areas of this topic from three angles; general information, cataloguing of photographs and anthropological research. The first area is the research on the general topic of post mortem photographs. This includes information such as; what qualifies as a post mortem photograph, historical facts about the practice, how morts can be identified and photographic processes used in the production of photographic morts.

The second section will look at cataloguing of photographs in museums, libraries and archives. This section will look at research into digitisation and use of photographs in the digital realm and a review of the core standards used in creating metadata for photographs, how libraries, museums and archives treat photographs differently with regards to original order, capsule collections, storage, restrictions etc. The final section will look at a small amount of the anthropological cross- over which relates to mourning and post mortem photography. This final area of research has a strong link to the first section as many pieces are chapters within larger publications relating to photography and death. Anthropologists such as George Batchen and Jay Ruby have published works looking at the cultural issues relating to photography of dead people in the $19^{\text {th }}$ century up to the present day.

An environmental scan of research relating to photographic morts uncovered that much of the study has been undertaken in America, a fact that did not come as a surprise. The majority of examples of post-mortem photography available today were taken between 1850-1930 in the United States. While looking at the number of post-mortem photographs digitised for public viewing - in museums, libraries, archives, private collection, privately owned museums and on sites such as eBay where one can buy an original post-mortem photograph for between $\$ 100-\$ 1000 \mathrm{US}$ the largest number appear in the American Midwestern states such as Iowa and 
Wisconsin. However, examples of post-mortem photography can be found from England to America, Australia, New Zealand, and into Eastern Europe. Many photographs are still available from the 1920-1940s from countries such as Lithuania, Estonia, Russia and Germany. The resurgence in Eastern Europe after the primary tradition had died away in the United Kingdom and America is another opening for further research.

Comparisons can be made between New Zealand collections and collections held in the United States. The reason for this is due to the proliferation of mort images in America, both in personal collections and held by institutions. By looking at the practice undertaken by high standing institutions such as The Library of Congress and Getty Museum, one may develop an idea of what lessons and experience can be gained by their greater level of research and experience with the subject.

\section{General mort history}

An essay by Nicola Bown written for the Australasian journal of Victorian studies, Empty hands and precious pictures: Post-mortem portrait photographs of children looks at morts within the context of mourning tradition, photographic, poetic and self-help books. Bown compared English/Welsh and Australian collections, making the comment at the lack of examples available in institutions. Bown goes into detail about how a mort photograph may be identified. The way the photograph has been set up, displaying items the family reserved for special occasions "The patterned wallpaper below the windowsill suggests that Alfred is lying in a parlour rather than a bedroom, for expensive wallpaper would have been reserved for rooms that might have been seen by visitors." (pp11)

Bown explains how one would identify a mort photograph. The people in these images often appear to be sleeping. For example the image Alfred Owens laid out after dead could on first appearance be of a child napping on a comfortable arm chair but Bown goes on to describe how the image can be identified as a mort. From his sunken eye lids, the particular detail taken in staging the photograph perfectly to the sunlight streaming in through the window as if it were light from heaven, Bown explains all the Victorian techniques to make a mort appear serene and beautiful.

An explanation of why the post-mortem image may not be visible in major institutional collections is given in the publication Suspending Time: Life-PhotographyDeath by George Batchen (2010). "No one has written much of substance about these kinds of photographs, of course, given they are vernacular, cheap, sentimental and extraordinarily common." (pp110)

The attitude towards social history in museums has not always been positive. It has not been until the present decade that such a keen interest in the everyday lives of normal people has been seen as vital in telling our historical stories. The "common and vernacular" have become the stories we are finally now interested in telling and 
from that we can hope more research into the traditions of everyday people may grow.

\section{Cataloguing and library procedures}

Research undertaken for this scan into the photographic standards for cataloguing images centred around AACR2 and RDA manuals. Many pieces written about cataloguing photographs such as Cataloguing visual images: the view from LC were written during the 1990s (1996 in the case of Harriet Harrison's piece) prior to digitising technological improvements and the inclusion of FRBR and RDA theories on cataloguing. Many articles focus on the use of basic Dublin Core standards when cataloguing a pictorial selection within a larger collection, particularly in the case of museum collections. Most library and archives collections observed during the literature review followed the AACR2 standards, particularly the additional rules in Chapter eight, Graphic Materials.

\section{Anthropological/social studies}

Jay Ruby's book Securing the shadow looks at both the historical and anthropological issues which arise when researching post-mortem photographs. "The photographs exposed in this study are not valuable because they are rare, unusual or "important art" but because they are useful in an exploration of attitudes towards death in America." (Ruby 1995 pp5) In saying this he outlines his intention to study the social culture of everyday people and how they viewed death and loss.

During his research Ruby discovered that the majority of photographic morts were commissioned by lower middle class families. His explanation of the lack of surviving mort photographs in society today, was based on interviews with families and individuals who believe many morts were destroyed by people during the years 1950-1980 as the societal feeling was that they were an example of unhealthy ideas surrounding death (Ruby 1995)

On closer analysis of the available research, the most visible gap is the lack of research into New Zealand mort photographs and context. There appears to be a variety of possible reasons why the photographs have not survived and the lack of collections in institutions, such as the changes in attitude towards death after the Second World War, and their common and sentimental subject matter. However it is not known if there ever was a wealth of post-mortem photographs in New Zealand. The focus of this research is to look at the way institutions catalogue sensitive cultural subjects such as death and mourning. From an anthropological perspective it is important to look at the cultural traditions from a New Zealand point of view and see if we followed the culture of other countries such as England and America or if our distinctive amalgamation of cultures has set us apart and changed the way we mourn our loved ones. 
The way Victorians viewed death was very forthright, honest and open which today may appear ghoulish, but the history of this tradition offers vital insights into how we have grown as a society and the break from our colonial roots. How has the distinctive blend of Pakeha and Maori culture affected the way we mourn and process the grief of lost loved ones? Research into our collective social history is becoming more valued in a Museum and Library context. Everyday life is now a worthy subject of research and will help us to understand how we have evolved into the nation we are today.

\section{Methodology}

The cataloguing of items in a library, museum or archive requires knowledge of and education in the standards and practice of cataloguing. There will only ever be a small number of staff working in the field of cataloguing heritage photographic material and even fewer who are in a position to write policy around the standards needed for description. It is due to this finite number of professionals available as possible interview candidates that the selection of interviewees needs to be by purposive sampling rather than a random population selection. Bryman (2012) states that purposive sampling "is conducted with reference to the goals of the research" pp 418. On this basis the interviewees will be selected by their knowledge of and experience in the field of photographic cataloguing and heritage materials.

Most large institutions will have policy or standards surrounding the description of collection items. The larger the institution the more likely they are to have collection specific, such as a photographic collection, guidelines for cataloguing. These documents will offer vital research into the practice followed by description staff and the training of new cataloguers.

The data collection method chosen for this study will be qualitative interviewing using triangulation with documents such as institutional policy and example catalogue records. This approach will allow the most well rounded view of practical application, official guidelines and past practice, illuminating any flaws or gaps which may to be approached. This research will endeavour to uncover the best practice of staff and official policy over the sample group of institutions and create guidelines for cataloguing of sensitive items (with a primary focus on photographs) at the Auckland War Memorial Museum.

In addition to the collection of catalogue records and policy documents during the first round of data collection, a selection of post-mortem photograph examples will be made from the institutional collections reviewed. The example records will be used during the interviews to flesh out discussions about current practice. The application of a visual ethnography approach will offer support to the documents and interviews in justifying the statements made about post-mortem photographs. 
"When based on extant photographs, they become the main source of data about the field in which the researcher is interested." (Bryman 2012 pp547)

\section{Research questions}

\section{Main question}

How are the post mortem photographs catalogued and what metadata is recorded by the description staff of New Zealand institutions?

How common were post mortem photographs in New Zealand during the years 1870-1940?

Are post-mortem photographs underrepresented in New Zealand institutions, or do our collections reflect the approximate number of morts created during the popular years of this practice?

\section{Sub questions}

\section{General questions}

- Which New Zealand institutions have post-mortem photographs in their collections?

- $\quad$ Are the post-mortem photographs available online?

- $\quad$ Do the institutions have post-mortem photographs catalogued but not digitised?

- Do the institutions have any 'hidden' collections? Either by choice of restriction or unprocessed collections.

- $\quad$ Are the post-mortem photograph part of a larger collection such as a family collection or photograph album?

- What kind of photographic processes are used for post-mortem photographs?

- How did the institutions acquire their post-mortem photographs? Donations, individual acquisition, large collection acquisition etc.

Cataloguing questions

- What metadata do the institutions retain about the post-mortem photographs?

- What Library of Congress subject headings are used to describe post-mortem photographs?

- What cataloguing standards do New Zealand institutions use to describe post-mortem photographs? AACR2, FRBR, RDA or basic Dublin Core? 
Anthropological questions

- What social trends in New Zealand (during the prescribed time period) are represented by the number of post-mortem photographs held in New Zealand Institutions?

- What cultural differences between New Zealand and other colonised countries can be hypothesised by the popularity of post-mortem photographs?

- What further questions for future arise from the information gained in this case study?

\section{Research collection methods}

The data collection for this study took place in two rounds. The first round was a comprehensive survey of the collections available online. This was followed by a series of general reference enquiries about holdings in a selection of museums, libraries and archives around New Zealand. The information gained from each institution offered a picture of what is available, both seen and unseen, in New Zealand institutions.

The general enquires were undertaken from the point of view of a walk-in customer. The enquiries included information on any material which was currently visible online in databases, any collections which had been restricted from public view and any collections which may contain post-mortem photographs but are uncatalogued or unprocessed. General enquiry emails were sent to the image department of each institution or in the case of a combined collection, the reference library staff. The final question asked as a part of the general enquiries was a request for the names of any staff whose duties involve the cataloguing of heritage photographs or the writing of policy for the description, acquisition and display of such collections. These enquiries followed the snow ball sampling method of extracting suitable interview candidates who would then be approached for round two of data collection.

Round two of data collection was subject to human ethics comity (HEC) approval and as such took place after approval had been granted. The second round involve face to face, telephone and/or email interviews with cataloguers, acquisitions staff, photographic collections technicians and policy makers for pictorial collection in New Zealand institutions. The interviews were semi structured. The questions were designed to touch on subjects such as; how any current mort photographs came to be in their collection? (e.g. by donation, acquisition, bequethment or as part of a larger collection.) Did staff believe we have fewer mort photos in New Zealand compared to other countries? What restrictions, if any, have the staff placed on the viewing, reproduction or digitizing of these images? How have the photographs been described? What subject headings are used? Are they dated? How the institution 
deals with the possible cultural issues relating to Maori collections, tapu or sensitive cultural topics? Have they created guidelines for dealing with sensitive items/images?

The questions posed for interviewees were modified between round one and the commencement of round two interviews. These changes and additions were based on the information gathered during the general enquiries from round one.

\section{Data analysis techniques}

The technique used for analysing the data collected was structured using a thematic approach. The choice of theoretical sampling rather than probability sampling or generic purposive sampling was most effective for this case study as it was an ongoing process of theoretical definition. Bryman states that theoretical sampling is used to "provide a springboard for the generation of theory, and the refinement of theoretical categories." (2012 pp 419) This approach best reflected the two levelled research design and use of triangulation between interview, policy and catalogue records which allowed the analysis of data to be an ongoing process throughout the document gathering, general enquiries and interviews stages.

All data was coded into themes and sub-themes, followed by the construct of a matrix to identify and highlight key ideas.

\section{Statement of results}

As mentioned in an earlier section the information gathering for this case study was under taken in two rounds; the first round was a series of general enquiries to large institutions from different areas around the country and the second was a series of interviews with Pictorial Curators/Librarians from the selected institutions.

\section{Round one}

The first round was styled on an everyday email enquiry which an institution would receive from a member of the public, ie a person without prior knowledge about collections other than the information available on the institutional websites. Each enquiry was sent to the pictorial department of the institution or in some cases the library. In total six institutions were contacted, four from the North Island and two from the South. Of the six institutions five responded, some with information upfront and others requesting information about why I required the images and what I planned to use them for. In reply to these queries I explained that I was a student researching for a master's paper and explained my topic and intentions for the findings. 
The data gathered from the first round of enquiries was based on general knowledge of the collection and a small amount of research to be prepared by pictorial staff to discover what items are held in their collections. Each email asked how many mort photographs they held, did the collection have more photographs which were not available online? (Either in full digitised records or restricted records which offered information but no image)

Each email also asked for the names of staff who worked as Pictorial Curators or Pictorial Librarians with the intention of contacting them for further information about the collections and how they are catalogued, following the snowball sampling technique. The statistics gathered from the emails were tabled in a spreadsheet for analysis and to offer comparisons between the six institutions contacted.

The bar chart in figure 1 shows the number of mort photographs held by the institutions surveyed. The blue (first) bar shows the number of mort photographs found on the institutions website and the red (second) bar shows how many were supplied by the institution during the general enquiries round. From this data it is clear that more mort photographs are held by the institutions than are available to the general public on the institutions websites.

Number of morts found

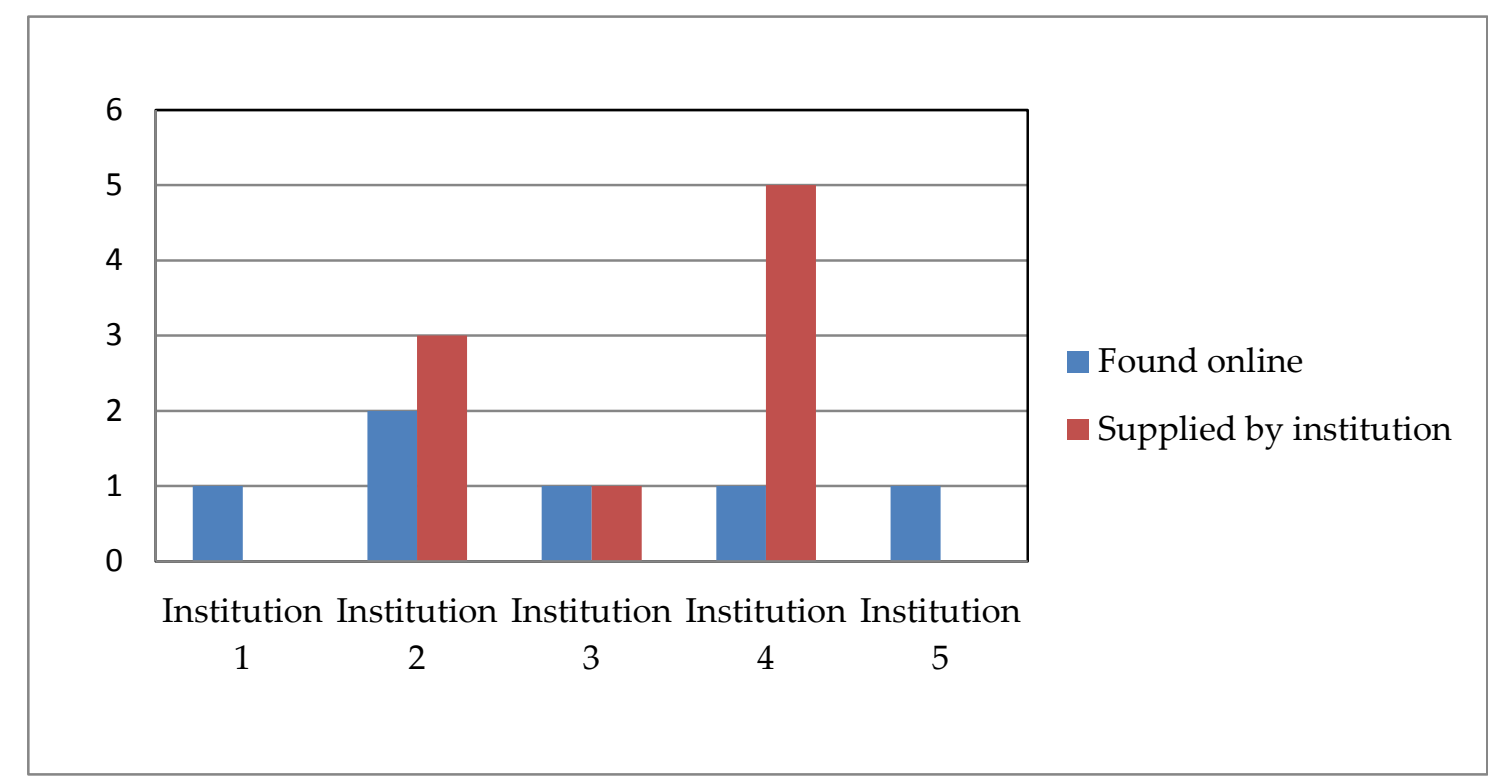

Fia. 1 
One of the questions posed in the general enquires round was; what photographic processes were used to create the morts held by each institution? If the information was not available on the catalogue or there was currently no record for the item, the question was directed to the enquiries service as a part of the enquiry email, either initially or in a follow up email conducted after the first information set came back from the institution.

Figure 2 shows the number of different processes used in the morts found. There are a limited number of processes used in comparison to other collections in the institutions.

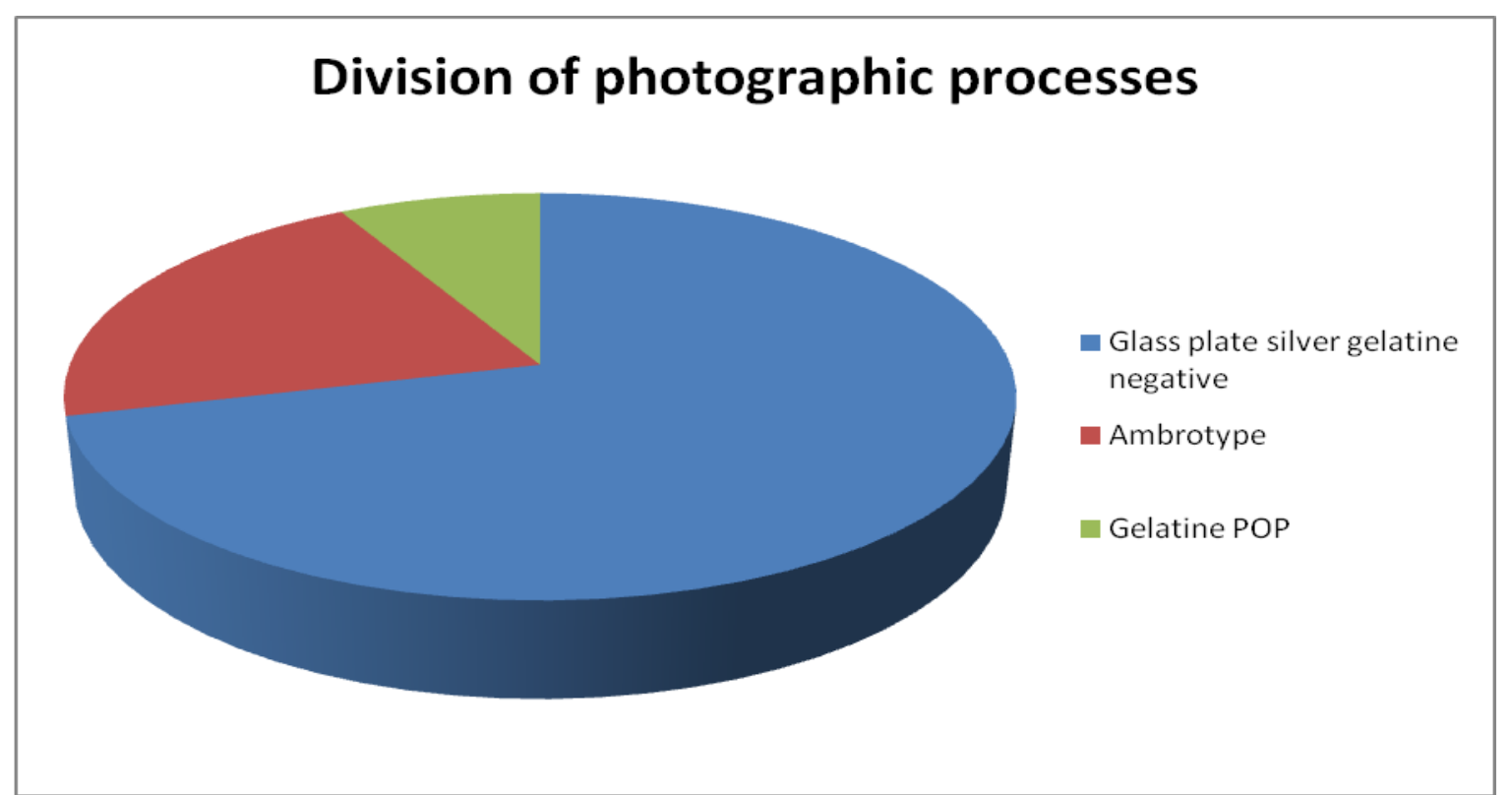

Fig. 2

The final question asked during initial enquiry was the name of a manager or collection head of department who could be contacted to request permission to interview a staff member at the institution. Each manager was sent an email outlining the project, the general themes and the ethical considerations which would be taken to ensure anonymity for the interviewee and the institution. See appendix for example letter. This process was in line with the Victoria University Human Ethics Comity guidelines. At this stage four out of five institutions who had replied to the initial enquiry were happy to offer institutional permission for interviews to take place at the discretion of the interviewee.

\section{Round two}

The makeup of round two data collection was a questionnaire delivered in person, over the phone or via email. Each interviewee was a Curator/Librarian presently working in the pictorial/photographic department of a New Zealand institution which held heritage photograph collections. Each collection had at least one mort photograph, accessible by online catalogue or by request during round one of data 
collection. Of the six institutions contacted five agreed to be interviewed and four gave institutional approval for interviews of their staff members. Four interviews took place over a 16 day period. The questionnaires sent to the interviewees consist of 10 questions, some made up of a single part question and some with two or three questions within the whole statement.

The two interviews which were in person/over the phone were recorded on a hand held device to allow for transcribing and the identification of significant quotes. Notes were also taken during the interviews. The two interviews structured into emails involved writing a word document containing the 10 questions which was filled out by the interviewee and sent back to the researcher. These interviews did not require transcription so they were coded into themes on the original form and quotes identified and referenced.

During the process of coding the information gathered during the interview stage it became clear that the major themes within the data reflected those uncovered during the literature review. The key themes could be divided into three categories; general information, cataloguing/policy/digitising and anthropological information. On closer inspection of the questions used for the interviews each could be identified as fitting into one of these themes and have been coded as such. In total four questions fell under the general information theme, four came under the cataloguing/policy/digitising theme and two related to anthropological considerations.

The first theme to emerge relates to the grouping of general facts about mort photographs in New Zealand collections, what are they, how many are available, when were they created, the process used etc. The benefit of this information is that general data gathered about mort photos held in New Zealand collections can be compared to collections of photographs held in other countries.

It will allow for comparisons of basic details such as age, cost, societal trends during the time of production and locality of images. For example by comparing the age of the images in New Zealand collection one may ascertain when the tradition was at its most popular in this country. These theories can be based on known dates of the photographs taken, by the clothing of the people in the images, the style used to pose the image and/or by the photographic process being used. These are all simple ways to make an educated guess about the age of an image.

The second theme which became apparent relates to cataloguing, metadata, digitising and policy surrounding the images. This theme relates to how photographs are represented in a surrogate and/or online function, whether the information is available to the public or just for institutional use. The relationship of the physical photographic item and the way it is represented in metadata form bring about a number of questions such as; what methods are used when cataloguing an 
image, the level of description and whether is varies from less sensitive topics and policies surrounding what level of metadata is available and to whom.

The final theme relates to the anthropological themes in the research. The questions relating to the cultures or nationalities of the people represented in mort photographs and what class of society is represented most frequently? The anthropological questions offer data into who was requesting the photographs and will allow researchers to offer theories as to why people followed the tradition. In doing so we can look at who was not taking part in the practice and look at future angles for research into why that may be.

\section{General mort themes}

Interview questions which came under general mort themes:

How would you define a mort photograph?

Are you aware of the number of mort photographs held in your repository?

Do you know the origins of the mort photographs in your collection? Are they part of a larger collection, single acquisition and/or donation?

How is the subject matter represented in these images e.g. the deceased laid out, caskets vs. sleeping pose?

The idea of what classifies a mort seemed to be unanimous among the interviewees. They all answered that a mort related to a recently deceased person laid out in a restful position. Often the photograph was commissioned by the family of the deceased and was created to memorialise a loved one. All four interviewees remarked that most examples they had encountered were of babies or children. One stated that the photographs most often were "presented in a manner appropriate to portraiture" (Anon, Personal communication, Nov 1, 2013) In saying this the interviewee draws the conclusion that in life or in death the human form is posed/manipulated in a similar way, rather than being represented as something other than the loved one they were prior to death. The result of this information can also be referred to the anthropological section of this research as well as it offers important details about how people in New Zealand society view the process of death and do not immediately feel detached from a person straight after death. The figures in New Zealand mort photographs are regarded in manner which has respect for the body and not as though it was a vessel for the soul which is no longer present.

The number of morts held in the institutions varied from 1-6. The most interesting point made by the interviewees was that they had no way of knowing the full extent of the collections holdings. In each interview it was mentioned that the institution retained a sizeable backlog in collections built up over many years. Each institution holds collections which were donated over a period of year and had not been 
processed since their arrival. The reason given for this is a lack of collections staff, time and funds. Another point along the same lines was that many images were catalogued at the parent level. An album may be catalogued but each individual image may not have been at this point in time "A lot of our collections are described at collection level or album level or box level." (Anon, Personal communication, Oct 30, 2013). For this reason all four interviewees left the number they may hold open ended as they may never know the full extent of such large collections holdings.

The origins of each collections morts are also not clearly definable. All four interviewees said their mort photographs had come to the institution via larger collections donated or acquired for reasons other than the mort images. For example a photographic studio attic collection discovered 60 years after the closure of the studio or a family collection spanning 100 years of history. One comment made related to the changes made in the way photographs are handled over the $100+$ years the institution had been collecting. "It is only in the last 20 years that the museum has had a more serious and through approach to collecting and recording metadata about photographic images." (Anon, Personal communication, Oct 30, 2013) The information available in these collections which has yet to be recorded may be an avenue for further research into this topic. The enthusiasm towards digitisation in the last few years has helped to bring to light many of the images which are now available in the institutions surveyed. "There are some, which are predominately portrait collections [where] the post mortem photographs have appeared, we've become aware of them through digitisation and description at item level." (Anon, Personal communication, Nov 1, 2013) The process of digitisation is not only important for interaction with the public and access to the collections but also allows more intensive research into the holdings of the larger collections down to individual items.

As seen in the literature review many details about the photograph can be ascertained by the position of the body in the photograph. Details such as the approximate year the image was taken, the class of the family and to some degree the religion of the deceased (often indicated by symbols, shape of floral wreaths or religious texts on or around the body)

For the collections scanned, the most common pose for a New Zealand post-mortem image is a child laid out in sleeping pose on a bed or in a cot. Some of the images found had the addition of a teddy bear or other toy, very often they had flowers on or around the body. One example found shows a mother in a seated pose with a young child on her knee wearing a long white Christening gown. The child could easily be mistaken for sleeping but from the inscription on the plate the viewer is informed that the baby is deceased. The pose of a child being held by their mother is very popular in America as many examples of mother and baby morts can be found in institutions across the States. It seems to be less common in New Zealand as this one image is the only one found during the enquiries. It can be hard to know if the image is a post mortem without any additional information such as a studio register or inscription especially if the original housing, such as an album or cabinet card has 
been lost. Two of the interviewees remarked at the grey area between tagging an image as possibly post mortem or not. They posed the question; is it better to warn the viewer prior to seeing an image on the catalogue if there is no way of knowing for sure that if the figure is deceased. In spite of additional information and research it can be difficult to determine if the figure is in their sick bed and perhaps not far from death or if they have already passed away and have been laid out for viewing.

The images of older people or older children (teen and above) focus more around the casket and the grandeur of the funeral. The adult images often reflect the traditions maintained when photographing influential people lying in state. For example showing the figure surrounded by a bounty of floral wreaths and symbols with an extreme attention to detail. At least one institution retains a born digital image as a part of their collection. Due to the age of the file the image was created in the last 15 years but very little other information seems to be available on the photograph. Data such as this shows the researcher that people are still choosing to follow the tradition of post-mortem photography, particularly with the death of a young child or still born baby.

\section{Cataloguing/digitisation/metadata/policy questions}

The questions which relate to the cataloguing theme:

Do you have a policy on restricting public access to sensitive images both in physical access and online? If so do mort photographs fall into this category? What are the parameters of the institutions policy?

How much description/metadata is added to your mort images? For example basic/skeletal or enhanced/researched information.

Are your mort photographs included in a digitisation strategy? If so how many are digitised and are they treated any differently due to the subject matter?

What standards are you using to catalogue your images/mort images? For example RDA, AACR2 or Dublin Core.

The cataloguing series of questions relates to the themes around how the images/items are handled once they are processed by an institution, the decisions which are made about them and the information which can be gathered and how it should be used/displayed. Each question relates to metadata collected by staff for use in a computerised information management system and finding aids.

Of the institutions surveyed one has a full ban on the digitising or displaying of human remains. The other three had a more relaxed case by case policy leaving much of the decision making up to the discretion of the Librarian or Curator. Each cataloguing systems in use by the four institutions has the capacity to; restrict an image if required, maintaining a digital file for institutional use and allowing the metadata to be viewed by the public. Many of the interviewees commented on their 
reluctance to fully restrict images as they saw public interaction with the collection as a valuable information gathering resource. At least two interviewees stated that they would support a more concrete policy on what can and cannot be made available on the institutions website. One interviewee commented on the need for some kind of warning which may alert a member of the public before they chose to view the image. In the case of a restricted image, one institution creates a catalogue note telling the viewer why the image has been restricted and that it can be viewed on request or in person.

There was unanimous agreement between the institutions interviewed that mort photographs are not intentionally treated any different when it comes to metadata applied to the catalogue records. One interviewee pointed out that because the images were not used in exhibitions or on display there may be less research done on them over the years. Many institutions base the level of detail added to their records on the demand from the public for the images. When an enquiry is made about an image, the pictorial technician or library assistant will research the history of the photograph and enrich the record where information is available. The demand for information on mort images remains minimal at present. Another interviewee remarked that it was not the level of metadata but the language used which was more sensitive in relation to sensitive photographs. When writing a description for a mort photograph, they may omit too detailed a description, for example leaving out the presence of blood or bruising. The question of needing to warn the viewer was again brought up and posed the question; is more information better so people aren't confronted unprepared with an image should they choose to view it?

All four institutions made comments about how their mort collections were neither included nor excluded from their digitisation plans. Often they will be digitised due to the systematic digitisation of some collections, for example portrait or cartes-deviste collections which may contain mort photographs. Often these large collections are outsourced and catalogued/digitised without any prior information regarding the specific content. Mort photographs have not been singled out for special treatment and as such often remain unrestricted online until a member of the public or staff brings the subject to the Librarians attention. All four interviewees said they would look into any public comment/approval/disapproval and work towards a solution for the specific image, generally the restriction of the digitised surrogate on the public website or updating of incorrect information on a record (in the case of a possible mort later identified as a living portrait)

The standards used by institutions were varied depending on; the kind of institution, where the collection resides within the institution and the individual history of the repository. Most standards used by the institutions surveyed can be mapped to the Dublin Core structure which identifies areas for basic resource description. Each institution has evolved their structure and cataloguing processes over a number of years and built on the basic structure with the addition of library specific guidelines such as AACR2 and RDA or museum more specific such as CCO 
or ISAD-G for more archive specific catalogues. The choice of cataloguing standards in the institutions surveys is a combination of legacy systems from restructures and the core requirements of the collection. One institution had a system created for their own use by a previous member of staff with a high level of knowledge in cataloguing and digitisation.

\section{Anthropological questions}

The questions which relate to anthropological themes:

Are you able to comment on how many Maori vs. European figures are represented in your mort collection?

In your opinion as a professional working in the heritage field, do you think mort photography is an underrepresented collection subject in New Zealand photographic institutions?

Each institution had a different mix of ethnicities in their mort photographs though over all the largest number where of European people. As a result of discussion a question arose relating to the treatment of a mort photograph of a Maori or Pacific Island figure. Would the interviewee compose the metadata differently or manage the display/digitisation in a different way than for that of a European figure? Two of the institutions said they would consult with the Maori Curator or Librarian and try to contact the family or Iwi to ask for permission to use the image. Both of the interviewees said they would treat a Maori mort with a bit more sensitivity due to the strong beliefs held in Maori culture around death and dying. One institution retains a mort photograph of a Pacific Island child and they have not treated the image any differently to the European examples.

The question of whether mort photography was under represented in New Zealand institutions was something all four interviewees had not considered prior to the initial enquiry. In spite of this each made significant points as to the position of morts in New Zealand society and their questionable popularity during the years 1860s-1940s. One interviewee remarked on the old fashioned ideas of past staff and how that lead to sensitive subjects being "hidden" or put aside to avoid the questions they posed. "When I first started working with our photograph collections I was amazed to find an almost secretive approach to taboo topics. For example I found a similar attitude to homosexuality in heritage photographs. Taboo collections were kept hidden and sometimes not even catalogued. That is perhaps one of the reasons we have so few mortuary photographs [in collections today]." (Anon, Personal communication, Nov 1, 2013) The interviewee hypothesised that such attitudes and the action of hiding the difficult topics from the public or the rest of the institution has led to the destruction or loss of some mort photographs over the past $60+$ years. The opinion of two of the interviewees was that with collections as large 
and as varied as they held, the lack of mort photographs lead them to believe that the tradition was not popular among the general public during the years it became popular in other countries. Some examples have been retained in collections showing that it was a practice which was engaged in but the scarce details and lack of examples lead the interviewees to believe that they would not come across a large amount of morts in the future. The final interviewee remarked that the lack of current interest in mort photographs may be the driving force into why we know so little about the practice in a New Zealand context. "Everything has its moment when people start to take notice and single it out as important. Historical photography, relating to commercial portraiture, is only starting to be regarded as having distinct genres and styles to be studied." (Anon, Personal communication, Oct 30, 2013)

The move towards research into social history and everyday subjects such as portraiture will offer more information into the important events in life such as death and mourning. With more research and public interaction hopefully more information in regards to the popularity, the destruction of or social feelings towards mort photographs may come to light.

\section{Analysis and discussion}

The intention of this study has been to discover whether heritage institutions in New Zealand treat mortuary photographs any differently than any other photographic collection due to their sensitive subject matter. The way the issue has been tackled has been to look at what we know about our collections; who has them, how old they are and what do they consist of, what we do with the photographs once they are held in a heritage institution; catalogue, digitise and/or exhibit, and what the photographs themselves can tell us about the culture of New Zealand and social history surrounding traditions of death and mourning. The underlying intention can be divided into specific themes, outlined earlier in the research questions.

It has become clear that the criteria for cataloguing mort photographs in heritage institutions are similar to that of any other photographic portraiture. Where a mort photograph may be treated differently is in the detail such as; the language used, the context within a larger collection, for example a family album or studio acquisition, and the use of the restrict function which all institutions surveyed had available.

The number of morts held in institutions was far fewer than initially expected. The initial hypothesis that a collection with very limited examples was missing a vital collection area in photographic heritage was incorrect. From the data collected in two rounds from six institutions across the country the average number of morts held is around 5. An average of 2 available on the public catalogue as digitised images and frequently 2-3 additional images were not catalogued or restricted. 
The most popular process for creating morts in New Zealand was the silver gelatine, glass dry plate negative. The data gathered about process offers insights into timeframe. The results show that morts were at the 'height' of popularity in New Zealand, between the years 1890-1920 after the invention of silver gelatine technology reached New Zealand.

The majority of morts uncovered during the research were images of babies and young children. The data reflects that the area of Victorian mourning tradition which caught on in New Zealand surrounded a parent's need for a visual representation of the child they lost and whose image was not able to be captured in a happier circumstance. The popularity of adult morts seems to have been limited in New Zealand with only occasional examples.

The discovery of numerous infant morts may give rise to further research questions and possible future study of infant mourning during the colonial growth of New Zealand culture. Very little information about where the images were taken was found but frequently by studying the movements of photographers and the studios who took the photographs one can conjecture that the people who undertook the practice primarily lived in the larger cities in New Zealand. Very few of the studios identified were from smaller town though there is always the possibility that the photographers travelled further than is reported in current research.

Another interesting difference to the researcher's initial hypothesis was a theory that the images would be consistently of people of European decent. The presence of a Pacific Island mort (the child of the King of Tonga) and occasional tangi images have shown that photography of the dead was not an anathema in these cultures. This too could be another area for further research; was the practice frowned upon or did it depend on the tribe/family/country? Do the "rules" change depending on the standing of the family in question?

In looking at the policies used by institutions it became clear that very few institutions had specific policy surrounding the use of and cataloguing of sensitive photographs. One institution had a full ban on using any images of human remains in exhibitions or online but the policy for images fell under a broader policy about the institutional guiding principles. The three remaining institutions left the decisions up to the discretion of the staff who work with the collections with scope for interaction with outside groups such as tribal leaders, other curators or families, if needed.

The deficiencies in this piece of research were primarily in the planning of the data collection. The number of institutions could have been wider as two of the intended repositories did not partake in the interviews. A larger data collection field would have offered more depth to the research and more knowledge from the Curators/Librarians who were interviewed.

The fundamental core of the information gathered, was in the statements/comments given by interviewees which showed the depth of knowledge into the collection 
these professionals have, information which could be vital in tracking the visual ethnology of New Zealand colonial culture.

A restructure of the time frame when gaining permissions would also have benefited the research. The time it took to find, contact and receive replies from the general enquiries, Curators/Librarians and subsequently the managers (once the interview candidates had agreed) was far longer than expected. In future consideration will be taken into how busy many staff at heritage institutions are on a day-to-day basis and schedule in a longer time for replies and ethical considerations.

The anthropological information gained from this research has uncovered many possible areas for research in the future. Research into the traditions which surrounded mourning in New Zealand, infant mortality and how we managed as a community with important life events such as births, deaths and marriages and how those events can be researched through the use of extant documents such as photographs.

A research area which has been under-developed in New Zealand is utilizing a large photographic collection as a document to look at the history of a community of people during a short space of time, for example the career of one photographer or one photographic studio.

\section{Conclusions}

Throughout the development of the preceding research the scope of intention has been substantially refined. From the primary question "Did New Zealand take part in the tradition of post-mortem photography?" the topic was refined to the handling and cataloguing of post-mortem photographs in heritage institutions in New Zealand and what facts such a tradition can offer about New Zealand social culture. The finding from; an extensive review of the international literature, a round of general enquiries, a round of interviews, the construction of a data collection methodology, collecting, coding and theme creation of the data and finally an analysis of the information gathered, have generated a wealth of concepts and further research avenues. The key learning from this research are that mort photography was not as popular in New Zealand as initially believed. The primary user group for mort photographs were families who had suffered the death of a babies or young children. The ethnic makeup of the figures in mort photographs is not limited to Europeans, exampled of Maori, Pacific Island and African American's were also found. When cataloguing and digitising mort photographs, institutions do not single out the images for different treatment, the distinctions occurred in the language and intention of the metadata available to the public. The way museums, libraries and archives manage their mort photographs is comparable though differing standards are applied to the style and organisation of the information. The reason is the intended audience of the collection differs, for 
example a library is frequently for public use, a museum for researchers and an archive for institutional use only. The final outcome of this case study is a documented change in the approach of the institutions surveyed. Each institution is working to dispel the historical environment of concealing and anathematising of sensitive topics, favouring instead an educational approach. Each institution expressed a genuine desire to engage with the community to enrich their collections, metadata and overall understanding of New Zealand society. 


\section{References}

Batchen, G. (2010) Suspending Time: Life-Photography-Death. Izu Photo Museum. Shizuoka,

Japan

Bell, J. (2005) Doing your research project: A guide for first-time researchers in education, health

and social science. Open University Press. England.

Bown, N. (2009) Empty hands and precious pictures: Post-mortem portrait photography of children. Australasian Journal of Victorian Studies. V14:2. Retrieved from Google Scholar on $9^{\text {th }}$ April 2013.

Olguin, S. (2010) Interactions with the non-human: Fetishism prosthesis and post-mortem. Anamesa. Volume 8. number 1. Retrieved from http://anamesajournal.wordpress.com/issues-2/spring-2010/ 19 May 2013.

Ruby, J. (1995) Secure in shadow: Death and photography in America. The MIT Press. Cambridge,

MA. USA. 


\section{Appendix}

Sample interview question for interviewees

Interview Questions

Lucy Gable, student 300167032

1. How would you define a mort photograph?

2. Are you aware of the number of mort photographs held in your repository?

3. Do you know the origins of the mort photographs in your collection? Are they part of a larger collection, single acquisition, donation etc.

4. Do you have a policy on restricting public access to sensitive images both in physical access and online? If so do mort photographs fall into this category? What are the parameters of the institutions policy?

5. How much description/metadata is added to your mort images? For example basic/skeletal or enhanced/researched information.

6. Are your mort photographs included in a digitisation strategy? If so how many are digitised and are they treated any differently due to the subject matter?

7. What standards are you using to catalogue your images/mort images? For example RDA, AACR2 or Dublin core?

8. Are you able to comment on how many Maori images vs European families are represented in your mort collections?

9. How is the subject matter represented in these mort photographs e.g. the deceased laid out caskets vs sleep pose?

10. In your opinion as a professional working in the heritage photography field, do you think mort photography is an underrepresented collection subject in New Zealand photographic institutions?

Sample letter to managers/institutions

Hi ...

My name is Lucy Gable and I am contacting you in regards to gaining your permission to interview the Curator of Photographs at

I am presently in the finally stages of my Master of Information Studies through Victoria University. My final assignment is a small piece of research which I have chosen to focus on the cataloguing of sensitive photographic materials within New Zealand heritage collections. I am currently working at the Auckland War Memorial Museum as a Collections Information Technician for Documentary Heritage under Shaun Higgins.

My research is based on a theoretical case study of metadata collected for post-mortem photographs, primarily focusing on the Victorian style of laying out deceased loved ones to retain an image of them to assist the grieving process. My research has looked at research and literature in the areas of cataloguing and metadata, the socio-anthropological history of post-mortem images and the history of the practice within photography (as a business primarily) 
My first round of research involved general enquiries to find out which institutions retained post-mortem images and what information they had in the catalogue records as available on their online catalogues.

My second round of information gathering involves short interviews (half an hour to 45 minutes over the phone) with Photographic Curators and Pictorial Librarians to ask about the choices they make and policies the institution holds about what information is made available to the public. For example do they digitise an image and make it available or do they restrict the image unless requested? Does the institution apply LC classifications to the mort photos if they are not $100 \%$ sure they are morts (sometimes it is very hard to tell) and how they have chosen to approach this topic in their records.

I have been in contact with and he/she has kindly agreed to be interviewed on my topic sometime at the beginning of next month.

To be granted human ethics approval from my university I am required to ask the institution for permission to interview their staff and I hope that on reading my email you will agree that this is an interesting and current topic for further research.

Please feel free to ask any questions you may have about how I will undertake my research, storage of information or ethical considerations or even if you'd just like to know more about it!

Thank you for your time and I will look forward to hearing from you.

Lucy Gable 